\title{
Social brain development in Williams syndrome: the current status and directions for future research
}

\author{
Brian W. Haas ${ }^{1,2 *}$ and Allan L. Reiss ${ }^{2}$ \\ ${ }^{1}$ Department of Psychology, The University of Georgia, Athens, GA, USA \\ ${ }^{2}$ Center for Interdisciplinary Brain Sciences Research, Stanford University School of Medicine, Stanford, CA, USA
}

Edited by:

Daniela Plesa Skwerer, Boston

University, USA

Reviewed by:

David Liu, University of California, San Diego, USA

Ruth Ford, Griffith University, Australia

*Correspondence:

Brian W. Haas, Department of Psychology, The University of Georgia, Athens, GA 30602-3013, USA. e-mail: bhaas@uga.edu
Williams syndrome (WS) is a neurodevelopmental condition that occurs as a result of a contiguous deletion of $\sim 26-28$ genes on chromosome 7q11.23. WS is often associated with a distinctive social phenotype characterized by an increased affinity toward processing faces, reduced sensitivity to fear related social stimuli and a reduced ability to form concrete social relationships. Understanding the biological mechanisms that underlie the social phenotype in WS may elucidate genetic and neural factors influencing the typical development of the social brain. In this article, we review available studies investigating the social phenotype of WS throughout development and neuroimaging studies investigating brain structure and function as related to social and emotional functioning in this condition. This review makes an important contribution by highlighting several neuro-behavioral mechanisms that may be a cause or a consequence of atypical social development in WS. In particular, we discuss how distinctive social behaviors in WS may be associated with alterations or delays in the cortical representation of faces, connectivity within the ventral stream, structure and function of the amygdala and how long- and short-range connections develop within the brain. We integrate research on typical brain development and from existing behavioral and neuroimaging research on WS. We conclude with a discussion of how genetic and environmental factors might interact to influence social brain development in WS and how future neuroimaging and behavioral research can further elucidate social brain development in WS. Lastly, we describe how ongoing studies may translate to improved social developmental outcomes for individuals with WS.

\section{Keywords: Williams syndrome, development, social, emotion, review}

\section{INTRODUCTION}

Williams syndrome (WS) is a neurodevelopmental condition that occurs in $\sim 1$ in every 8,000 live births and arises as a result of a contiguous deletion of $\sim 26-28$ genes on chromosome $7 \mathrm{q} 11.23$. Individuals with WS are characterized by a compelling psychological phenotype comprised of relative strengths and weaknesses across multiple cognitive domains and with a distinctive pattern of social behavior (Martens et al., 2008). One of the most compelling aspects of the WS social phenotype is an increased appetitive drive toward social interaction (Jarvinen-Pasley et al., 2008). People with WS will often approach others, including strangers, with little to no regard of potential negative consequences. In terms of development, many parents and caregivers of children with WS are challenged by the task of teaching their children to behave in socially appropriate ways. Studies designed to elucidate the trajectory of social functioning and brain development in WS are a critical step toward the design and implementation of targeted intervention techniques that promote healthy social development in affected individuals and may elucidate important genetic and neural factors influencing the normal development of the social brain.

The goal of this article is to present a framework for how the social brain develops in WS. We will review empirical evidence characterizing the social phenotype throughout development and evidence characterizing alterations of brain regions important for social functioning in WS. We will discuss how atypical brain development may relate to distinctive social behaviors in WS. Lastly, we will discuss ongoing and future research on social brain development in WS and discuss the value of cross-disciplinary research in terms of elucidating how the social brain develops in WS.

\section{SOCIAL PHENOTYPE AND THE SOCIAL BRAIN IN WILLIAMS SYNDROME}

The social phenotype associated with WS is in stark contrast to social phenotypes associated with many other neurodevelopmental conditions. For example, while individuals with autism or fragile X tend to be "socially distant" or averse to approaching others (Reiss and Hall, 2007), individuals with WS are often described as being "hypersocial." Approaching strangers, fixating on faces, and speaking in close proximity to others, are all characteristic behaviors associated with WS. One of the earliest published reports on WS described a group of WS patients as having the "same kind of friendly nature" and that "they love everyone, are loved by everyone, and are very charming" (Beuren et al., 1962). The apparent increased sociability often ascribed to people with WS has motivated the design of many studies focused on elucidating the social phenotype of WS. 


\section{PERSONALITY, TEMPERAMENT, AND SOCIABILITY IN WILLIAMS SYNDROME}

Approaches to investigating social functioning in WS include performing observational research and quantifying the manner in which parents of children with WS characterize their child's social behavior. Evidence from observational research indicates that children with WS make more efforts to socially engage others as compared to children with autism (Lincoln et al., 2007), display fewer socio-communicative abnormalities than children with autism (Klein-Tasman et al., 2009) and are more willing to approach strangers relative to typically developing (TD) controls (Dodd et al., 2010). These studies suggest that in naturalistic settings, children with WS display a distinctive pattern of social behavior characterized by an increased affinity toward social interaction relative to children who are autistic or TD.

Many studies have demonstrated that parents of children with WS rate their child as being more "overtly social" as compared to parents of TD children. For example, parents rate children with WS as displaying higher "intensity" of social approach relative to parents of TD children (Tomc et al., 1990). These parents also rate their child with WS as being less reserved around strangers (Gosch and Pankau, 1994) and more "globally social" (Doyle et al., 2004; Zitzer-Comfort et al., 2007) relative to parents of TD children. Together, these studies indicate that children with WS are consistently characterized as being more likely to socially interact with others as compared to children with other neurodevelopmental conditions and those who are TD.

\section{FACE PROCESSING IN WILLIAMS SYNDROME}

Individuals with WS tend to process faces atypically. Specifically, people with WS tend to focus more attention on faces and socially relevant cues (e.g., eyes) as compared to controls. As evidenced by eye-tracking, people with WS fixate on faces longer (Riby and Hancock, 2008, 2009) and are slower to disengage their gaze once fixated on eyes (Porter et al., 2010) or a face (Riby et al., 2010) relative to controls. Lastly, observational research during social interactions has shown that children with WS tend to hold gaze on faces for a prolonged period of time relative to TD children (Mervis et al., 2003; Doherty-Sneddon et al., 2009). Together, these findings suggest that an increased tendency to focus on faces may be associated with the overt, highly motivated, drive toward social interaction commonly observed in WS.

Although individuals with WS may have a spared (or even heightened) affinity toward processing faces, the manner in which the cognitive mechanisms supporting face recognition develop in WS is currently not well understood. For example, there is evidence indicating that individuals with WS tend to recognize and distinguish faces based on individual features comprising a face (such as the eyes and the mouth, indicating feature based processing), while TD individuals tend to recognize and distinguish faces based on the configuration of the entire face (i.e., the overall arrangement of the features of the face or "configural" based processing) (Deruelle et al., 1999; Karmiloff-Smith et al., 2004; Isaac and Lincoln, 2011). Conversely, there are also reports of spared configural or holistic face processing in WS (Tager-Flusberg et al., 2003; Deruelle et al., 2006; Annaz et al., 2009). Together, these findings support the hypothesis that development of face processing in WS follows an atypical trajectory (Leonard et al., 2011). However it is currently unclear if the developmental trajectory of face processing in WS is better described as "deviant," "delayed" or a combination of both as compared to that of the TD trajectory.

\section{EMOTION PROCESSING IN WILLIAMS SYNDROME}

Individuals with WS tend to process emotions atypically. In particular, those with WS are less able to detect social fear signals as compared to controls. Plesa-Skwerer et al. (2006) showed that individuals with WS are less able to perceive negative emotions conveyed through facial expressions and voices relative to controls. Furthermore, those with WS are less accurate in detecting the presence of angry faces during a visual search task (Santos et al., 2010) and are less aroused in response to angry faces (PlesaSkwerer et al., 2009) or scenes (Plesa-Skwerer et al., 2011) relative to controls. These studies suggest that the reduced ability to detect social threat signals may be an important factor related to the tendency to uninhibitedly approach strangers in WS.

Recently, evidence has emerged that persons with WS exhibit a bias toward processing positive emotional facial expressions. For example, those with WS rate happy facial expressions as more approachable (relative to other emotions), as compared to controls (Frigerio et al., 2006). Additionally, individuals with WS tend to focus a greater amount of attention on happy faces (relative to other emotions) as compared to controls (Dodd and Porter, 2010). Combined, these studies indicate that WS is associated with a reduced ability to detect social threat signals (e.g., fear and angry faces) and an increased bias toward processing positive social signals (e.g., happy faces) and support the hypothesis that WS is associated with atypical or delayed development of emotion processing.

\section{BEHAVIORAL INHIBITION}

Williams syndrome is associated with poor social inhibition that may in part in be related to deficits in inhibition in general (Porter et al., 2007). For example, individuals with WS may approach others such as strangers due to a reduced ability to inhibit the urge to socially interact with others. Behavioral studies have shown that individuals with WS typically commit more errors during response inhibition tasks as compared to controls (Menghini et al., 2010) and also experience more difficulties inhibiting their emotions as compared to controls (Mervis and Klein-Tasman, 2000). In addition, deficits in response inhibition have been shown in children with WS as young as 18 months of age (Cornish et al., 2007). Recent evidence however, indicates that deficits in response inhibition may be primarily related to IQ as opposed to social functioning in WS (Capitao et al., 2011a) suggesting that atypical social behavior may be, in part, secondary to cognitive impairments. Combined, problems in inhibiting behavior and emotions are characteristics of the WS phenotype and may be related to the distinctive pattern of social behavior in this condition.

\section{HIGHER ORDER SOCIAL-COGNITIVE FUNCTIONS}

Individuals with WS often demonstrate difficulties in higher order social-cognitive functions manifested by atypical non-verbal communication, imagination, and problems in understanding the mental states of others (i.e., theory of mind). For example, while 
playing in a group, children with WS exhibit less spontaneous functional play and imaginary play compared to TD children (Papaeliou et al., 2011). Those with WS are less accurate in labeling emotions from brief dynamic facial displays (Skwerer et al., 2006) and are less accurate when tested with several types of theory of mind tasks (Porter et al., 2008; Santos and Deruelle, 2009). TagerFlusberg and Sullivan (2000) argued that the social-cognitive component of theory of mind is compromised in WS while the social perceptual component of theory of mind is spared. In summary, there is considerable evidence that WS is associated with difficulties in processing complex social-cognitive information and that social-cognitive development is either atypical and/or delayed in WS.

\section{EARLY CHILDHOOD}

Children with WS exhibit a distinctive pattern of social behavior during early development. Infants and young children with WS (ages 8-43 months) exhibit greater amounts of extended, intense gaze toward the faces of others relative to controls (Mervis et al., 2003). Children with WS (age from 1 year, 1 month to 12 years, 10 months) consistently score higher on several measures of sociability (parental ratings) as compared to controls (Doyle et al., 2004). Lastly, as measured by the Multidimensional Personality Questionnaire-Parent Version (Tellegen, 1985), children with WS (ages 8-10 years) are characterized as being relatively more gregarious, people-oriented, and sensitive as compared to controls (Klein-Tasman and Mervis, 2003). Combined, these studies demonstrate that from an early age ( 8 months), children with WS exhibit behaviors consistent with the tendency to be more driven to socially interact as compared to controls.

\section{SUMMARY: SOCIAL PHENOTYPE OF WILLIAMS SYNDROME}

Empirical research has shown that several aspects of social functioning are atypical during development in WS (Table 1). Specifically, WS is associated with atypical (i) personality: high gregariousness, intensity, and global sociability (Tomc et al., 1990; Klein-Tasman and Mervis, 2003; Doyle et al., 2004), (ii) face processing: increased focus on faces and eyes (Riby and Hancock, 2008, 2009), (iii) emotion processing: reduced ability to detect social threat signals (Plesa-Skwerer et al., 2006, 2009; Santos et al., 2010) and increased attentional bias toward positive social signals (Dodd and Porter, 2010), (iv) reduced ability to inhibit behavior (Porter et al., 2007; Menghini et al., 2010) and emotions (Mervis and Klein-Tasman, 2000), and (v) reduced ability to understand the mental states of others (Tager-Flusberg and Sullivan, 2000; Porter et al., 2008; Santos and Deruelle, 2009). The a distinctive pattern of social behavior in WS is present during very early stages of development (as early as 8 months; Mervis et al., 2003) and is persistent throughout adulthood (Elison et al., 2010).

\section{THE SOCIAL BRAIN IN WILLIAMS SYNDROME}

Williams syndrome is associated with atypical functional anatomy of brain regions important for social behavior and emotional processing. Considerable evidence derived from brain imaging research indicates that alterations of the fusiform face area (FFA), amygdala and connections within the brain are important neural substrates associated with the social phenotype in WS. More
Table 1 | Summary of social phenotype of WS.

\begin{tabular}{|c|c|}
\hline Aspect of social function & Abnormality in WS \\
\hline Personality & $\begin{array}{l}\text { High gregariousness, intensity and global } \\
\text { sociability }\end{array}$ \\
\hline Face processing & Increased focus on faces and eyes \\
\hline Emotion processing & $\begin{array}{l}\text { Reduced ability to detect social threat } \\
\text { signals } \\
\text { Increased attentional bias toward positive } \\
\text { social signals }\end{array}$ \\
\hline Inhibition & $\begin{array}{l}\text { Increased number of errors during } \\
\text { response inhibition tasks } \\
\text { Reduced ability to regulate emotions }\end{array}$ \\
\hline Higher order social cognition & $\begin{array}{l}\text { Reduced ability to understand the mental } \\
\text { states of others }\end{array}$ \\
\hline
\end{tabular}

specifically, alterations of the FFA are likely associated with atypical face processing, alterations of the amygdala may be linked to atypical emotion processing and altered connectivity within the ventral stream and frontostriatal pathway may be linked to distinctive patterns of social behavior and emotion processing. In the following section, we will review studies that have investigated the neural substrates of social behavior and emotion processing in WS.

\section{BRAIN REGIONS INVOLVED IN FACE PROCESSING}

Williams syndrome is associated with altered structure and function within brain regions important for face processing. The fusiform gyrus is located on the inferior medial surface of the temporal lobe and is functionally involved in object and face recognition. Magnetic resonance imaging (MRI) studies have demonstrated that the structure of the fusiform gyrus is atypical in WS. For example, using a 3D cortical surface modeling approach, Thompson et al. (2005) demonstrated that adults with WS exhibit greater cortical gray matter thickness of the fusiform gyrus relative to TD adults. Reiss et al. (2004) used a voxel based morphometry (VBM) approach to show greater gray matter density within the fusiform gyrus in adults WS as compared to TD controls. Campbell et al. (2009) also used VBM to show reduced gray matter volume in the left fusiform and increased gray matter volume in the right fusiform in children and adolescents with WS (age range: 8-16 years) relative to TD children and adolescents. Together, these studies indicate that atypical structure of the fusiform gyrus may be an important neural substrate associated with the distinctive pattern of face processing in WS.

Within the fusiform gyrus, the FFA is a highly specialized region for face recognition (Kanwisher et al., 1997). In TD individuals, activation within the FFA is consistently greater when responding to faces vs. other types of stimuli such as houses (Kanwisher and Yovel, 2006) and is correlated with the ability to detect the presence of faces (Grill-Spector et al., 2004). One way to elucidate how the FFA functions in atypical and typical populations is to use functional magnetic resonance imaging (fMRI). fMRI is a particularly advantageous tool to investigate the extent to which brain regions are responsive during the processing of specific types of stimuli. Mobbs et al. (2004) used fMRI and demonstrated that individuals with WS exhibit greater activation within the fusiform gyrus when 
responding to faces relative to TD controls. In another study from our laboratory, we used fMRI and a face processing task to quantify the volume of the FFA within a group of adults with WS relative to a TD control group (Figure 1; Golarai et al., 2010a). The results of this study showed that although individuals with WS exhibit a reduced total volume of the fusiform gyrus (structurally defined), the volume of the FFA (functionally defined) is larger in WS relative to TD controls. Additionally, we found that the functional volume of the FFA is correlated with face recognition accuracy in WS. Recently, O'Hearn et al. (2011) also reported that the FFA is larger in WS relative to controls and showed that the cortical representation of other types of stimuli (e.g., houses) is relatively smaller in WS.

\section{BRAIN REGIONS INVOLVED IN EMOTION PROCESSING}

Williams syndrome is associated with atypical structure and function within brain regions important for processing emotions. The amygdala is located within the medial temporal lobe and is involved in assessing the emotional salience of stimuli within the environment (Aggleton, 2000). MRI studies have shown that the volume of the amygdala is greater in WS relative to controls. For example, using a manual delineation, region of interest (ROI) approach Reiss et al. (2004) demonstrated that the total gray matter volume of the amygdala (after controlling for total brain volume) is greater in adults with WS relative to TD controls. Other studies have used similar approaches and have similarly reported greater amygdala volumes in WS relative to controls (Martens et al., 2009; Capitao et al., 2011b). Furthermore, the results of a combined structural MRI and behavioral study by Martens et al. (2009) demonstrated that the volume of the amygdala is correlated with approachability ratings of emotional facial expressions in WS. These findings suggest that an enlarged volume of the amygdala may be associated with atypical emotion processing in WS.

In addition to structural alterations, WS is associated with atypical amygdala response to social-emotional stimuli. MeyerLindenberg et al. (2005) used fMRI to show that adults with WS exhibit a reduced, or blunted, amygdala response to fearful facial expressions as compared to TD controls. Our group has replicated this finding (Haas et al., 2009; Mimura et al., 2010). In addition, we demonstrated that amygdala response to fearful facial expressions is correlated with the tendency to approach strangers in WS (Haas et al., 2010; Figure 2).

Interestingly, in contrast to the pattern of amygdala response to fearful facial expressions, individuals with WS exhibit greater amygdala response to happy facial expressions relative to controls (Haas et al., 2009). Combined, these findings suggest that reduced amygdala response to fearful facial expressions may be a neural substrate associated with the tendency to uninhibitedly (or

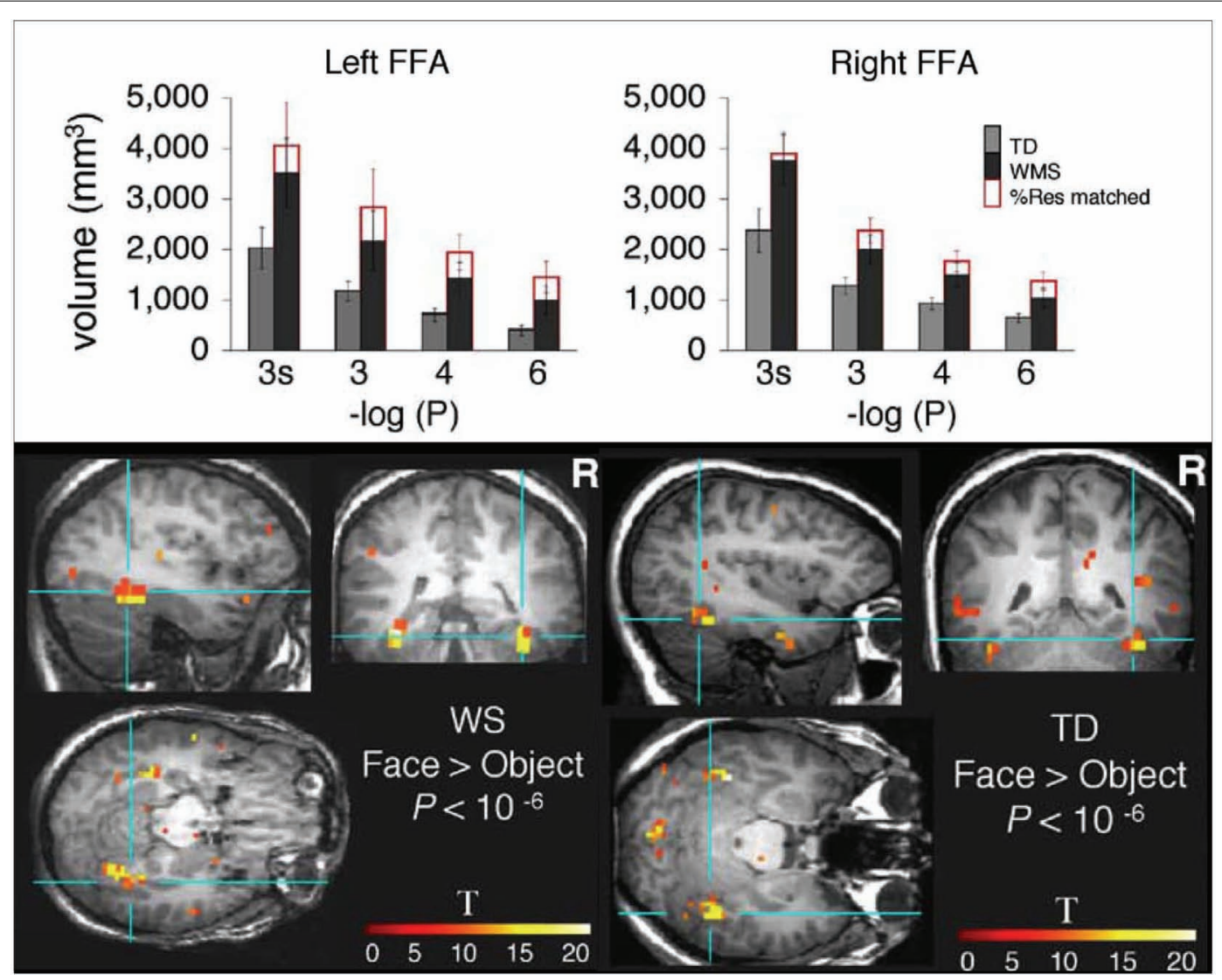

FIGURE 1 |The FFA is larger in WS (Williams syndrome) compared to TD (typically developing) adults. Upper panel: Bars represent the volume of the FFA (functionally defined) as defined by various statistical thresholds and smoothing techniques. Images presented in the lower panel display an FFA defined on a WS brain (left) and a TD brain (right). Adapted from Golarai et al. (2010a) the Journal of Neuroscience. 


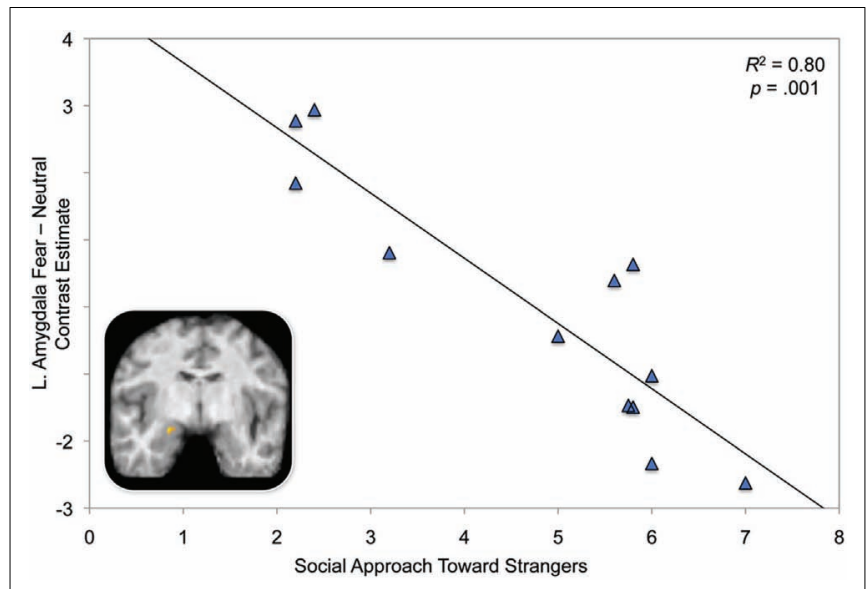

FIGURE 2 | Individual differences in social behavior (Social Approach Toward Strangers scores) associated with left amygdala response to fearful, compared to neutral, facial expressions in WS. Tendency to approach strangers (as rated by a caregiver) are plotted on the $x$-axis. Contrast estimates within the left amygdala are plotted on the $y$-axis. Adapted from Haas et al. (2010) Neuropsychologia.

"fearlessly") approach strangers in WS, while increased amygdala response to happy facial expressions may be a neural substrate associated with the tendency to be more "driven" (or motivated) to approach others.

\section{BRAIN CONNECTIONS INVOLVED IN FACE AND EMOTION PROCESSING}

Williams syndrome is associated with atypical anatomical and functional connectivity between brain regions important for face and emotion processing. Sarpal et al. (2008) demonstrated that when processing facial expressions, individuals with WS exhibit less functional connectivity between the FFA and amygdala relative to controls. Our group recently used a diffusion tensor imaging (DTI) approach to show that individuals with WS exhibit an increase in the volume, fractional anisotropy, and fiber density index of white matter fibers projecting through the fusiform gyrus in WS relative to controls (Haas et al., 2012; Figure 3). In addition, Mobbs et al. (2007) showed that during a response inhibition task, individuals with WS fail to recruit frontostriatal circuitry implicated in inhibition. This finding suggests that WS is associated with altered connectivity between striatal areas and prefrontal cortices. Together, these results support the hypothesis that the neural pathways that serve to connect brain regions important for social, emotional and inhibitory processing are atypical in WS.

\section{SUMMARY: THE SOCIAL BRAIN IN WILLIAMS SYNDROME}

Neuroimaging research has elucidated how several neural substrates may be associated with the distinctive social phenotype in WS (Table 2). Specifically, WS is associated with: (i) altered structure of the fusiform gyrus (Reiss et al., 2004; Thompson et al., 2005; Campbell et al., 2009), (ii) larger volume of the FFA (Golarai et al., 2010a; O’Hearn et al., 2011), (iii) larger amygdala volume (Reiss et al., 2004; Martens et al., 2009; Capitao et al., 2011b), (iv) altered amygdala function: reduced response to fearful facial expressions (Meyer-Lindenberg et al., 2005; Haas et al., 2009) and heightened response to happy facial expressions (Haas et al., 2009), and (v) altered connectivity associated with the fusiform cortex and amygdala (Sarpal et al., 2008; Haas et al., 2012) and within frontostriatal pathways (Mobbs et al., 2007). Together, these findings demonstrate that in adulthood, WS is characterized by altered functional anatomy of brain regions important for social behavior and emotion processing. In addition, these studies provide support to the hypothesis that the development of neural circuitry important for social and emotional functioning is atypical in WS.

\section{SOCIAL BRAIN DEVELOPMENT IN WILLIAMS SYNDROME}

Integrating findings from behavioral and neuroimaging research can potentially provide insight as to how altered or delayed brain development contributes to, or results from atypical social behavior in WS. Behavioral research has demonstrated that distinctive patterns of social behavior and emotion processing exist early in childhood in WS (Mervis et al., 2003) and that the acquisition of social-emotional skills follows an atypical trajectory in affected individuals (Annaz et al., 2009; Leonard et al., 2011). Neuroimaging research has demonstrated that during adulthood, the functional anatomy of brain regions important for socialemotional processing is altered in WS (Reiss et al., 2004; Haas et al., 2009; Martens et al., 2009; Golarai et al., 2010a). In the following section we will discuss how the social brain may exhibit an atypical or delayed developmental pattern in WS. We will draw evidence from studies reviewed within the previous section of this article and from research on social brain development in healthy populations.

\section{CORTICAL REPRESENTATION OF FACES}

During typical development, the FFA grows in volume throughout childhood (Golarai et al., 2007; Peelen et al., 2009) and late adolescence (Golarai et al., 2010b), ultimately stabilizing in volume in early adulthood. The trajectory of FFA development is typically more prolonged as compared to the development of ventral stream areas allotted to processing other types of visual stimuli (Peelen et al., 2009; Golarai et al., 2010b). Increased FFA volume during development is associated with improved face recognition memory performance (Golarai et al., 2007, 2010b). In terms of the cognitive mechanisms underlying face processing, the development of feature based face recognition occurs more rapidly than configural based face recognition (Mondloch et al., 2002) and fMRI research has demonstrated separate networks within the fusiform gyrus specialized for these different face processing mechanisms (Maurer et al., 2007). Overall, typical development of the cortical representation for processing faces is a dynamic process that extends through late adolescence and is associated with dissociable cognitive-behavioral aspects of face processing (i.e., featural vs. configural based).

As we have discussed, adults with WS exhibit a disproportionately greater area of the fusiform gyrus allotted to processing faces (FFA), as compared to the fusiform region allotted to processing other types of visual stimuli (Golarai et al., 2010a; O'Hearn et al., 2011). Further, one might speculate that, during childhood, fusiform components specialized for specific aspects of face processing (i.e., featural vs. configurual) may develop more rapidly or be spared relative to fusiform regions specialized for other aspects of face processing in WS. The differential development of 


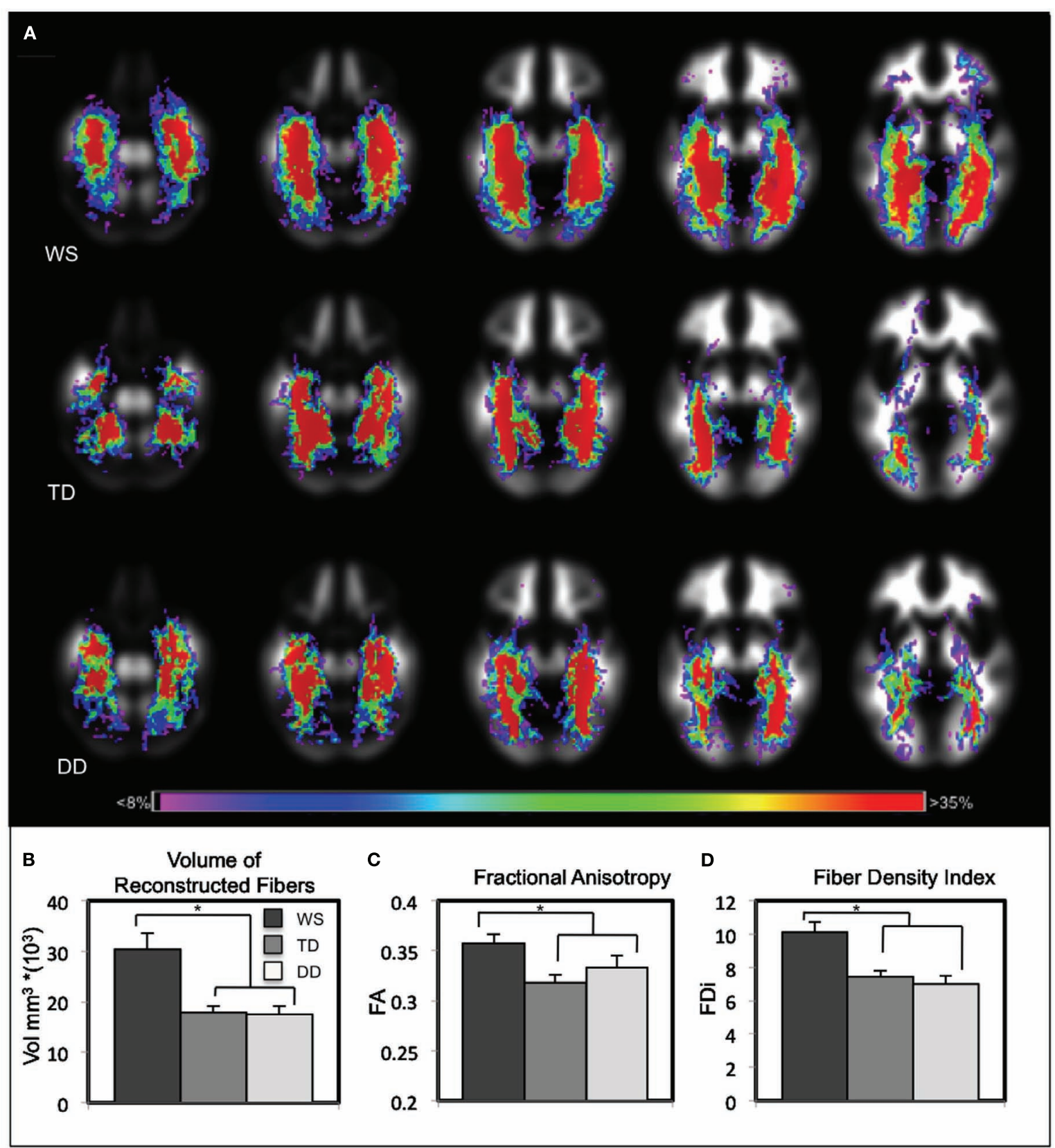

FIGURE 3 | Reconstructed white matter fibers projecting through the fusiform gyrus in the WS (Williams syndrome), TD (typically developing), and DD (developmentally delayed) groups. Color scale within probabilistic maps (A) corresponds to the relative probability of reconstructed fibers being present at each location, within each group. Plots of macro- [(B) volume of reconstructed fibers] and micro- [(C) fractional anisotropy and (D) fiber density index] for fibers projecting through the fusiform gyrus in WS, TD and DD participants. Vol $\mathrm{mm}^{3}$, volume in millimeters; FA, fractional anisotropy; FDi, fiber density index; ${ }^{*} p<0.05$. Error bars represent standard error from the mean. Adapted from Haas et al. (2012) Genes, Brain, and Behavior. cortical areas within the fusiform gyrus in WS may be a primary or secondary neural substrate associated with increased attention to faces (Riby and Hancock, 2008, 2009) and a reduced ability to identify objects and places based on visuo-spatial cues (Paul et al., 2002; Landau et al., 2006; Lakusta et al., 2010).

\section{VENTRAL STREAM CONNECTIVITY}

In typical development, white matter develops rapidly throughout the first 2 years of life (Gao et al., 2009) and continues to develop throughout adulthood (Kochunov et al., 2010). Studies using DTI have demonstrated that major white matter pathways within the brain exhibit differential rates of development (BarneaGoraly et al., 2005; Eluvathingal et al., 2007; Kochunov et al., 2010). For example, the results of a DTI study by Kochunov et al. (2010) indicated that the fronto-occipital tract (part of the inferior fronto-occipital fasciculus: IFOF) matures at a faster rate relative to the superior longitudinal fasciculus (SLF). Functionally, the IFOF is an important pathway related to the ability to process 
Table 2 | Summary of neural substrates of social-emotional functioning in WS.

\begin{tabular}{ll}
\hline Neural substrate & Abnormality in WS \\
\hline $\begin{array}{l}\text { Structure of fusiform } \\
\text { gyrus }\end{array}$ & $\begin{array}{l}\text { Increased gray matter thickness } \\
\text { Increased gray matter volume in the right fusiform } \\
\text { Volume of fusiform } \\
\text { face area (FFA) }\end{array}$ \\
Amygdala structure & $\begin{array}{l}\text { Increased volume } \\
\text { Reduced response to fearful faces }\end{array}$ \\
Amygdala function & $\begin{array}{l}\text { Increased response to happy faces } \\
\text { Reduced functional connectivity between the FFA } \\
\text { and amygdala } \\
\text { Increased volume of white matter fibers related } \\
\text { to the fusiform } \\
\text { Reduced activation within the frontostriatal } \\
\text { pathway }\end{array}$ \\
\end{tabular}

faces (Thomas et al., 2008) and emotions (Philippi et al., 2009). For example, Philippi et al. (2009) showed that focal lesions of the IFOF are associated with impaired recognition of emotional facial expressions. Combined, these studies indicate that white matter matures rapidly during early brain development and that the structural integrity of the IFOF is associated with face and emotion processing.

It is possible that altered development of the IFOF in WS may be a cause or a consequence for some of the distinctive patterns of face processing in this condition. For example, rapid or spared development of the IFOF may occur in contrast to relatively delayed or impaired development of dorsal stream pathways important for visuo-spatial functioning such as the SLF. DTI studies in adults with WS provide preliminary support for this hypothesis. For example, Marenco et al. (2007) demonstrated that adults with WS exhibit greater lattice index (LI: a measure of microscopic directional organization) of white matter fibers within the IFO (part of the IFOF), as compared to controls. Hoeft et al. (2007) demonstrated that altered structural integrity of the SLF is associated with visuo-spatial deficits in adults with WS. Lastly, in a recent study from our laboratory, we demonstrated that white matter fibers projecting through the fusiform gyrus (likely overlapping with fibers within the IFOF) were greater in volume, fractional anisotropy and density in WS relative to controls (Haas et al., 2012; Figure 3). Rapid or spared development of the IFOF and delayed or impaired development of the SLF may be a primary or secondary neural substrate associated with increased affinity to processing faces and delayed visual-spatial functioning in WS.

\section{AMYGDALA NUCLEI}

During typical development, the amygdala increases in volume between the ages of 4 and 18 years of age (Giedd et al., 1996; Durston et al., 2001). Functionally, younger children (3.5-8.5 years of age) exhibit greater amygdala response to happy, relative to angry faces, whereas adults exhibit greater amygdala response to angry, relative to happy faces (Todd et al., 2010). Nuclei within the amygdala are anatomically distinct and exhibit different (and interactive) functional roles (Aggleton, 2000; Balleine and Killcross, 2006). For example, the basolateral nucleus receives input from sensory cortices (Saygin et al., 2011) and some studies have suggested is primarily involved in the formation of stimulusvalue associations during fear conditioning (LeDoux et al., 1990; Koo et al., 2004). Other amygdala nuclei have been shown to serve different functions. For example the central nucleus is thought to be preferentially involved in the moderation of appetitively motivated learning processes (Knapska et al., 2006; Mahler and Berridge, 2009; Lee et al., 2010). While the spatial resolution of fMRI substantially limits the ability to accurately differentiate structure-function associations of amygdala nuclei in humans (Ball et al., 2009), single-unit recording studies in primates have reported on the presence of specific emotion (e.g., aversive vs. pleasant) selective neurons within the amygdala (Paton et al., 2006; Belova et al., 2007). Overall, these studies indicate that the structure and function of the amygdala develops throughout childhood and there is evidence that amygdala nuclei are anatomically and functionally dissociable. In addition, there is some evidence that the basolateral nucleus may be particularly engaged during the processing of negative social stimuli (LeDoux et al., 1990; Koo et al., 2004) while other nuclei, such as the central nucleus, may be particularly engaged during the processing of positive social stimuli (Knapska et al., 2006; Mahler and Berridge, 2009; Lee et al., 2010).

In WS, the amygdala nuclei important for processing socialemotional signals may not develop normally and may either be a cause or a consequence of atypical patterns of emotion processing. In adults with WS, regions within the amygdala that exhibit altered reactivity to fearful and happy faces appear to have a different functional topography. For example, the results of an fMRI study from our laboratory indicated that the location of the amygdala cluster found to be more responsive to fearful faces in TD controls is relatively more inferior (peak MNI $z$ coordinate $=-20$ ) compared to the location of the cluster found to be more responsive to happy faces in WS (peak MNI $z$ coordinate $=-14$; Haas et al., 2009; Figure 4).

In may also be the case that WS is associated with delayed (as opposed to atypical) development of the amygdala. As with TD children (Todd et al., 2010), adults with WS exhibit greater amygdala reactivity to happy (relative to negative emotional) facial expressions (Haas et al., 2009). Thus, in WS the amygdala may be delayed in terms of developing a heightened sensitivity to negatively valenced (socially related) stimuli.

Another intriguing theory regarding amygdala development in WS involves the association between the amygdala and serotonin function. Specifically, differential development of amygdala nuclei in WS may, in part, be associated with the serotonin system. This hypothesis is supported by evidence that mouse models of WS exhibit altered serotonin metabolism within the amygdala (Young et al., 2008) and that the basolateral and central nuclei within the amygdala differ according to the amount of serotonergic innervation (Lehmann et al., 2003). Lastly, there is some evidence that serotonin transmission may be related to the social phenotype of WS (Reiss et al., 1985; Proulx et al., 2010). Taken together, atypical or delayed development of the amygdala, and 


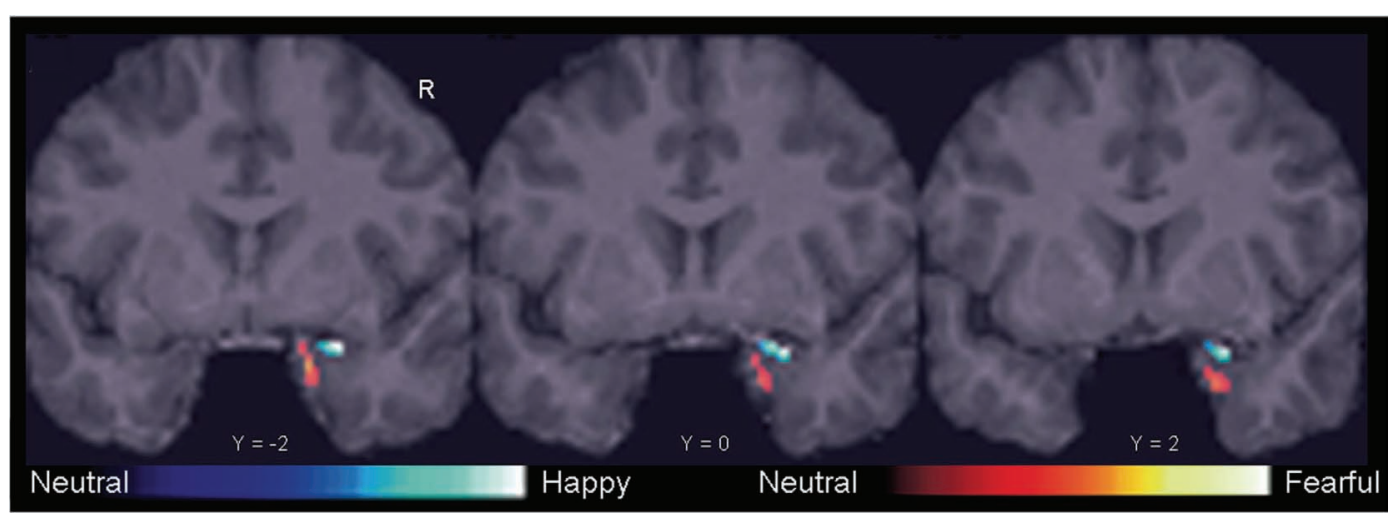

FIGURE 4 | Areas of greater right amygdala reactivity to fearful and happy facial expressions (compared to neutral) within the Williams syndrome (WS) and typically developing (TD) groups. Voxels of greater activation in response to happy versus neutral facial expressions in the WS group are designated by cold colors (blue). Voxels of greater activation in response to fearful versus neutral facial expressions in the TD group are designated by hot colors (orange). Adapted from Haas et al. (2009) Journal of Neuroscience. serotonergic function within the amygdala, may be an important cause or consequence of distinctive patterns of emotion processing in WS.

\section{DISTRIBUTED NETWORK}

Throughout typical childhood development, the amount of information processed locally decreases while the amount of information processed throughout a distributed neural network increases (Uddin et al., 2010; Vogel et al., 2010). For example, Supekar et al. (2009) used a combined functional connectivity and DTI approach to show that childhood brain development is associated with a weakening of short-range and a strengthening of long-range connectivity. Interestingly, increased long-range connectivity (such as within the brain's default mode) is thought to be a neural construct associated with the development of complex, higher order social-cognitive abilities such as self-reflection and theory of mind (Uddin et al., 2007; Spreng et al., 2009).

Throughout typical development, many other changes occur in terms of how the cortex of the brain is structurally organized. For example, the complexity of cortical folding patterns (i.e., gyrification) peaks during early childhood and then decreases throughout late childhood, adolescence, and adulthood (Raznahan et al., 2011). Alterations of gyral and sulcal patterns are associated with cortical fiber connections (Takahashi et al., 2011) and thus are related to how neuronal signals are integrated throughout the brain (White et al., 2010). Models of cortical complexity suggest that many factors that include synaptic pruning, neuronal packing density, differential expansion of cellular layers and/or tissue types (gray vs. white matter) affect the emergence of cortical folding patterns throughout typical development (Van Essen, 1997; White et al., 2010; Mangin et al., 2011). In summary, during typical development, the connections within the brain, as well as the organization of the cortex, undergo many functional, and structural changes that likely correspond with the development of complex social-cognitive functions.

In WS, aberrant development of long- vs. short-range connectivity patterns may be a cause or a consequence of atypical abilities underlying the integration of social-cognitive stimuli. Individuals with WS exhibit spared (or even heightened) ability to process specific, simple types of social stimuli (i.e., features of faces; Karmiloff-Smith et al., 2004; Annaz et al., 2009; Isaac and Lincoln, 2011), but exhibit delays in integrating large sets of social-cognitive information (Tager-Flusberg and Sullivan, 2000; John and Mervis, 2010). In WS, the development of long-range connectivity patterns may be delayed with respect to short-range connectivity patterns. Aberrations of distributed long-range neural networks in WS may in part be associated with how the brain is globally organized. Indirect evidence for this hypothesis comes from findings showing that overall, the WS brain (in adulthood) is smaller in volume ( 12\%; Reiss et al., 2004; Thompson et al., 2005), has a relatively lower proportion of white matter (Thompson et al., 2005) and has a more complex pattern of cortical folding (Schmitt et al., 2002; Kippenhan et al., 2005; Van Essen et al., 2006) relative to the TD brain. Interestingly, fMRI studies have reported preserved local activation paired with reduced functional connectivity when individuals with WS perform visual-spatial (Meyer-Lindenberg et al., 2004) and social-cognitive (Sarpal et al., 2008) tasks. Lastly, there is evidence that individuals with WS exhibit alterations in neuronal development. For example, post mortem studies (in humans) have shown that WS is associated with an increase in packing density of neurons (Galaburda and Bellugi, 2000) and animal models of WS exhibit alterations in synaptic plasticity and dendritic spine morphology (Osborne, 2010). In summary, alterations or delays in how distributed long-range networks develop in WS may be an important neural correlate of deficits in higher order social-cognitive functions in WS.

\section{GENE X ENVIRONMENT INTERACTIONS}

Although there is considerable support for a model relating genetic risk in WS to atypical brain development, ultimately influencing distinctive social behaviors in this condition, it is also important to consider the influence of environmental factors. Altered neural circuitry may also be a consequence of atypical social behavior and/or environmental factors operating throughout development in WS. It is well established that genes and environmental factors 
interact with one another to influence many psychological traits (Dick, 2011). In addition, it is well recognized that the trajectory and severity of symptoms associated with many neurodevelopmental conditions are affected by environmental factors (Reiss and Dant, 2003; Zahir and Brown, 2011).

Though individuals with WS are at significant risk for demonstrating characteristic features of the behavioral phenotype discussed above, persons with this condition also exhibit considerable variability in cognitive ability and social functioning. In terms of cognitive abilities, Berman and colleagues have reported on an atypical group of individuals with WS that exhibit relatively normal IQ (Meyer-Lindenberg et al., 2005; Marenco et al., 2007; Sarpal et al., 2008), while the majority of individuals with WS exhibit IQ scores between 50 and 60 (Martens et al., 2008). The fact that there can be considerable variability across cognitive functions in WS suggests that other factors, such as those related to the environment and genes outside the critical WS deletion region on chromosome 7, may be at play.

In terms of social behavior, it is also clear that there exists considerable variation in how emotions and social stimuli are processed in WS. For example, Porter et al. (2008) demonstrated that individuals with WS exhibit significant heterogeneity across several measures related to theory of mind. In addition, we have described how individuals with WS exhibit variability in the tendency to approach strangers and that variation in social behavior is associated with amygdala response to fearful facial expressions (Haas et al., 2010; Figure 2). Although gene by environment interactions in WS has yet to be thoroughly investigated, this may be a promising avenue for future research.

\section{TYPICAL SOCIAL BRAIN DEVELOPMENT AS INFORMED BY WS}

By understanding the neural substrates of distinctive patterns of social behavior and emotion processing in WS, a greater understanding of how the typical social brain develops can be achieved. Additionally, because WS is linked to a specific and well defined contiguous genetic deletion, the study of individuals with this condition has the potential to provide important information pertaining to genetic factors that influence development of the typical social brain.

Recent studies on animal models of WS suggest that specific genes may be associated with the development of brain regions important for social behavior. For example, Feyder et al. (2010) utilized a histological approach in knockout mice and showed that Cyln2 expression (a candidate gene for WS) and DLG4 variation are associated with subtle dysmorphology of amygdala dendritic spines. These findings suggest that $C y \ln 2$ and $D L G 4$ may interact with one another to influence the development of the social brain.

Other studies of humans with partial WS deletions also support the hypothesis that specific genes may influence the development of the social brain. Dai et al. (2009) compared the social behavior of an individual with a large portion of the WS affected genes deleted, but spared GTF2I, to a group with the full WS deletion. Results indicated that the individual with a spared GTF2I gene was less social as compared to the group with the full WS deletion. Together, these findings suggest that some of the WS affected genes (including Cyln2 and GTF2I) may influence the typical development of the social brain.

\section{FUTURE DIRECTIONS}

In this article we have presented a framework of how the social brain may develop in WS by using an integrative approach. We have described how particular neural mechanisms may be associated with the development of atypical social behavior and emotion processing in this condition. Future research using prospective, longitudinal designs paired with advanced neuroimaging techniques and behavioral measurement approaches will be critical to further elucidating social brain development in typical development and in WS. Below, we describe specific research strategies that may further elucidate social brain development in WS.

A potential strategy to elucidate how the cortical representation of faces develops in WS is to measure the volume of the FFA in a longitudinal fashion throughout childhood and adolescent development in WS using a face processing task and high-resolution fMRI (Golarai et al., 2007, 2010b). Tasks involving the presentation of different types of visual stimuli (including faces, objects and houses) are effective tools to quantify the proportion of the fusiform gyrus specifically responsive to faces vs. other visual stimuli (Berman et al., 2010). This strategy allows for statistical comparisons to be made regarding brain regions specialized for face processing in spite of potential structural differences within the fusiform gyrus associated with diagnosis or age (Grill-Spector et al., 2008). In addition, by pairing functional neuroimaging with behavioral face processing tasks in a longitudinal study, insight as to increased FFA volume either serving as a cause or a consequence to increased attention to faces in WS may be obtained.

Studies designed to elucidate how connections within the ventral stream develop in WS may include measuring the integrity of major white matter pathways within the brain during development by using a combined DTI and functional connectivity approach (Ramnani et al., 2004). DTI is a particularly advantageous tool to measure condition specific alterations in white matter (Thomason and Thompson, 2011) and developmental changes in brain connectivity patterns (Johnston, 2008). Combining DTI with functional connectivity approaches is particularly useful to better understanding how white matter pathways contribute to processing information between critical brain regions (Guye et al., 2008). Using this approach may be useful in testing the hypothesis that the rate of development of pathways within the ventral stream, such as the IFOF, occurs differently as compared to dorsal pathways, such as the SLF, in WS.

A potential strategy to elucidate amygdala development in WS is to measure the anatomy and function of amygdala nuclei on a longitudinal basis during childhood and adolescence (SolanoCastiella et al., 2011). Additionally, the use of an approach designed to quantify surface contours of the amygdala (in vivo) may provide insight as to how amygdala regions differentially develop in WS (Kim et al., 2011). Lastly, we may gain insight as to the development of amygdala function in WS by using fMRI paired with tasks including both positive and negative social stimuli (Gao and Maurer, 2009).

Lastly, studies designed to investigate how distributed neural networks develop in WS may include resting state fMRI combined with DTI and advanced analysis strategies such as functional connectivity and graph theoretical analyses. It may also be advantageous to include the assessment of higher order social- 
cognitive functions such as theory of mind throughout development. Such approaches can be useful in characterizing the development of short vs. long-range connections within the brain (Supekar et al., 2009; Power et al., 2010) and may be used to test hypotheses that posit associations between distributed neural networks and the development of higher order social-cognitive functions (Uddin et al., 2007; Spreng et al., 2009) in WS.

\section{CLINICAL IMPLICATIONS}

Teaching appropriate social behavior to children with WS is among the most frequent challenges that parents and caregivers of children with WS report (Eleanor and Rosner, 2003). Furthermore, there are many clinical examples of adults with WS exhibiting persistent distinctive social behaviors that ultimately hinders their ability to lead normal lives (Bedeschi et al., 2011). Research that elucidates how distinctive social behaviors develop in WS is a critical step toward the design of effective intervention techniques that serve to improve social developmental trajectories in WS.

Understanding social brain development in WS may facilitate the design of novel intervention techniques. By understanding the trajectory of brain development in WS, clinicians may be better informed as to the optimal time to intervene. For example, Annaz et al. (2009) demonstrated that between the ages of 5.6-12.1 years, children with WS exhibit an emerging specialization to process individual features of faces (featural-based face processing - i.e., eyes and mouth), rather than holistically (i.e., the whole face combined). Therefore, one might predict that the 5-12 year age range may be a particularly advantageous developmental stage for interventions designed to improve face processing in WS. The use of brain imaging at multiple time points during development may

\section{REFERENCES}

Aggleton, J. P. (2000). The Amygdala: A Functional Analysis. New York: Oxford University Press.

Annaz, D., Karmiloff-Smith, A., Johnson, M. H., and Thomas, M. S. (2009). A cross-syndrome study of the development of holistic face recognition in children with autism, Down syndrome, and Williams syndrome. J. Exp. Child. Psychol. 102, 456-486.

Ball, T., Derix, J., Wentlandt, J., Wieckhorst, B., Speck, O., SchulzeBonhage, A., and Mutschler, I. (2009). Anatomical specificity of functional amygdala imaging of responses to stimuli with positive and negative emotional valence. $J$. Neurosci. Methods 180, 57-70.

Balleine, B. W., and Killcross, S. (2006). Parallel incentive processing: an integrated view of amygdala function. Trends Neurosci. 29, 272-279.

Barnea-Goraly, N., Menon, V., Eckert, M., Tamm, L., Bammer, R., Karchemskiy, A., Dant, C. C., and Reiss, A. L. (2005). White matter development during childhood and adolescence: a cross-sectional diffusion tensor imaging study. Cereb. Cortex 15, 1848-1854.

Bedeschi, M. F., Bianchi, V., Colli, A. M., Natacci, F., Cereda, A., Milani, D., Maitz, S., Lalatta, F., and Selicorni, A. (2011). Clinical follow-up of young adults affected by Williams syndrome: experience of 45 Italian patients. Am. J. Med. Genet. A. 155A, 353-359.

Belova, M. A., Paton, J. J., Morrison, S. E., and Salzman, C. D. (2007). Expectation modulates neural responses to pleasant and aversive stimuli in primate amygdala. Neuron 55 , 970-984.

Berman, M. G., Park, J., Gonzalez, R., Polk, T. A., Gehrke, A., Knaffla, S., and Jonides, J. (2010). Evaluating functional localizers: the case of the FFA. Neuroimage 50, 56-71.

Beuren, A. J., Apitz, J., and Harmjanz, D. (1962). Supravalvular aortic stenosis in association with mental retardation and a certain facial appearance. Circulation 26, 1235-1240.

serve as an important tool to measure the efficacy of interventional approaches for altering the structure and function of specific neural circuits in WS as has been suggested for other neurodevelopmental conditions such as fragile X (Fung et al., 2012). Lastly, as with the WS behavioral phenotype, the neural signature of WS is characterized by both typical and atypical elements. By understanding the neural mechanisms that are typical in WS, clinicians may be better positioned to design intervention approaches that capitalize on relative strengths to improving relative deficits.

\section{SUMMARY AND CONCLUSIONS}

In this article, we have reviewed studies on the social phenotype of WS from childhood to adulthood. These studies demonstrate that WS is characterized by an affinity towards social interaction and that the trajectory of acquiring social-cognitive functions is either atypical or delayed in WS. Neuroimaging studies have demonstrated that during adulthood, WS is associated with many alterations within the neural circuitry important for social behavior and emotion processing. We used an integrative approach and described how the social brain may develop in WS. We also described how future research may further inform models of neural and behavioral developmental mechanisms in WS. In conclusion, there remain many intriguing questions regarding how the social brain develops in WS. We anticipate that research on social brain development in WS will further elucidate models of typical development of the social brain and will translate to improved developmental outcomes for affected individuals in the future.

\section{ACKNOWLEDGMENTS}

This study was supported by grants P01 HD033113-12 (NICHD) and T32 MH19908

Campbell, L. E., Daly, E., Toal, F., Stevens, A., Azuma, R., KarmiloffSmith, A., Murphy, D. G., and Murphy, K. C. (2009). Brain structural differences associated with the behavioural phenotype in children with Williams syndrome. Brain Res. 1258, 96-107.

Capitao, L., Sampaio, A., Fernandez, M., Sousa, N., Pinheiro, A., and Goncalves, O. F. (2011a). Williams syndrome hypersociability: a neuropsychological study of the amygdala and prefrontal cortex hypotheses. Res. Dev. Disabil. 32, 1169-1179.

Capitao, L., Sampaio, A., Sampaio, C., Vasconcelos, C., Fernandez, M., Garayzabal, E., Shenton, M. E., and Goncalves, O. F. (2011b). MRI amygdala volume in Williams Syndrome. Res. Dev. Disabil. 32, 2767-2772.

Cornish, K., Scerif, G., and KarmiloffSmith, A. (2007). Tracing syndromespecific trajectories of attention across the lifespan. Cortex 43, 672-685.

Dai, L., Bellugi, U., Chen, X. N., PulstKorenberg, A. M., Jarvinen-Pasley, A., Tirosh-Wagner, T., Eis, P. S.,
Graham, J., Mills, D., Searcy, Y., and Korenberg, J. R. (2009). Is it Williams syndrome? GTF2IRD1 implicated in visual-spatial construction and GTF2I in sociability revealed by high resolution arrays. Am. J. Med. Genet. A 149A, 302-314.

Deruelle, C., Mancini, J., Livet, M. O., Casse-Perrot, C., and de Schonen, S. (1999). Configural and local processing of faces in children with Williams syndrome. Brain Cogn. 41, 276-298.

Deruelle, C., Rondan, C., Mancini, J., and Livet, M. O. (2006). Do children with Williams syndrome fail to process visual configural information? Res. Dev. Disabil. 27, 243-253.

Dick, D. M. (2011). Gene-environment interaction in psychological traits and disorders. Annu. Rev. Clin. Psychol. 7, 383-409.

Dodd, H. F., and Porter, M. A. (2010). I see happy people: attention bias towards happy but not angry facial expressions in Williams syndrome. Cogn. Neuropsychiatry 15, 549-567. 
Dodd, H. F., Porter, M. A., Peters, G. L., and Rapee, R. M. (2010). Social approach in pre-school children with Williams syndrome: the role of the face. J. Intellect. Disabil. Res. 54, 194-203.

Doherty-Sneddon, G., Riby, D. M., Calderwood, L., and Ainsworth, L. (2009). Stuck on you: faceto-face arousal and gaze aversion in Williams syndrome. Cogn. Neuropsychiatry 14, 510-523.

Doyle, T. F., Bellugi, U., Korenberg, J. R., and Graham, J. (2004). "Everybody in the world is my friend" hypersociability in young children with Williams syndrome. Am. J. Med. Genet. A 124, 263-273.

Durston, S., Hulshoff Pol, H. E., Casey, B. J., Giedd, J. N., Buitelaar, J. K., and van Engeland, H. (2001). Anatomical MRI of the developing human brain: what have we learned? J. Am. Acad. Child Adolesc. Psychiatry 40, 1012-1020.

Eleanor, S., and Rosner, S. R. (2003). Understanding Williams Syndrome: Behavioral Patterns and Interventions. New York: Routledge.

Elison, S., Stinton, C., and Howlin, P. (2010). Health and social outcomes in adults with Williams syndrome: findings from cross-sectional and longitudinal cohorts. Res. Dev. Disabil. 31, 587-599.

Eluvathingal, T. J., Hasan, K. M., Kramer, L., Fletcher, J. M., and Ewing-Cobbs, L. (2007). Quantitative diffusion tensor tractography of association and projection fibers in normally developing children and adolescents. Cereb. Cortex 17, 2760-2768.

Feyder, M., Karlsson, R. M., Mathur, P., Lyman, M., Bock, R., Momenan, R., Munasinghe, J., Scattoni, M. L., Ihne, J., Camp, M., Graybeal, C., Strathdee, D., Begg, A., Alvarez, V. A., Kirsch, P., Rietschel, M., Cichon, S., Walter, H., Meyer-Lindenberg, A., Grant, S. G., and Holmes, A. (2010). Association of mouse Dlg4 (PSD95) gene deletion and human DLG4 gene variation with phenotypes relevant to autism spectrum disorders and Williams' syndrome. Am. J. Psychiatry 167, 1508-1517.

Frigerio, E., Burt, D. M., Gagliardi, C., Cioffi, G., Martelli, S., Perrett, D. I., and Borgatti, R. (2006). Is everybody always my friend? Perception of approachability in Williams syndrome. Neuropsychologia 44, 254-259.

Fung, L. K., Quintin, E. M., Haas, B. W., and Reiss, A. L. (2012). Conceptualizing neurodevelopmental disorders through a mechanistic understanding of fragile X syndrome and Williams syndrome. Curr. Opin. Neurol. 25, 112-124.

Galaburda, A. M., and Bellugi, U. (2000). V. Multi-level analysis of cortical neuroanatomy in Williams syndrome. J. Cogn. Neurosci. 12(Suppl. 1), 74-88.

Gao, W., Lin, W., Chen, Y., Gerig, G., Smith, J. K., Jewells, V., and Gilmore, J. H. (2009). Temporal and spatial development of axonal maturation and myelination of white matter in the developing brain. AJNR Am. J. Neuroradiol. 30, 290-296.

Gao, X., and Maurer, D. (2009). Influence of intensity on children's sensitivity to happy, sad, and fearful facial expressions. J. Exp. Child. Psychol. 102, 503-521.

Giedd, J. N., Vaituzis, A. C., Hamburger, S. D., Lange, N., Rajapakse, J. C., Kaysen, D., Vauss, Y. C., and Rapoport, J L. (1996). Quantitative MRI of the temporal lobe, amygdala, and hippocampus in normal human development: ages 4-18 years. J. Comp. Neurol. 366, 223-230.

Golarai, G., Ghahremani, D. G., Whitfield-Gabrieli, S., Reiss, A., Eberhardt, J. L., Gabrieli, J. D., and Grill-Spector, K. (2007). Differential development of high-level visual cortex correlates with categoryspecific recognition memory. Nat. Neurosci. 10, 512-522.

Golarai, G., Hong, S., Haas, B. W., Galaburda, A. M., Mills, D. L., Bellugi, U., Grill-Spector, K., and Reiss, A. L. (2010a). The fusiform face area is enlarged in Williams syndrome. J. Neurosci. 30, 6700-6712.

Golarai, G., Liberman, A., Yoon, J. M., and Grill-Spector, K. (2010b). Differential development of the ventral visual cortex extends through adolescence. Front. Hum. Neurosci. 3:80. doi:10.3389/neuro.09.080.2009

Gosch, A., and Pankau, R. (1994). Social-emotional and behavioral adjustment in children with Williams-Beuren syndrome. Am. J. Med. Genet. 53, 335-339.

Grill-Spector, K., Golarai, G., and Gabrieli, J. (2008). Developmental neuroimaging of the human ventral visual cortex. Trends Cogn. Sci. (Regul. Ed.) 12, 152-162.

Grill-Spector, K., Knouf, N., and Kanwisher, N. (2004). The fusiform face area subserves face perception, not generic within-category identification. Nat. Neurosci. 7, 555-562.

Guye, M., Bartolomei, F., and Ranjeva, J. P. (2008). Imaging structural and functional connectivity: towards a unified definition of human brain organization? Curr. Opin. Neurol.21, 393-403.

Haas, B. W., Hoeft, F., Barnea-Goraly, N., Golarai, G., Bellugi, U., and Reiss, A. L. (2012). Preliminary evidence of abnormal white matter related to the fusiform gyrus in Williams syndrome: a diffusion tensor imaging tractography study. Genes Brain Behav. 11, 62-68.

Haas, B. W., Hoeft, F., Searcy, Y. M., Mills, D., Bellugi, U., and Reiss, A. (2010). Individual differences in social behavior predict amygdala response to fearful facial expressions in Williams syndrome. Neuropsychologia 48, 1283-1288.

Haas, B. W., Mills, D., Yam, A., Hoeft, F., Bellugi, U., and Reiss, A. (2009). Genetic influences on sociability: heightened amygdala reactivity and event-related responses to positive social stimuli in Williams syndrome. J. Neurosci. 29, 1132-1139.

Hoeft, F., Barnea-Goraly, N., Haas, B. W., Golarai, G., Ng, D., Mills, D., Korenberg, J., Bellugi, U., Galaburda, A., and Reiss, A. L. (2007). More is not always better: increased fractional anisotropy of superior longitudinal fasciculus associated with poor visuospatial abilities in Williams syndrome. J. Neurosci. 27, 11960-11965.

Isaac, L., and Lincoln, A. (2011). Featural versus configural face processing in a rare genetic disorder: Williams syndrome. J. Intellect. Disabil. Res. 55, 1034-1042.

Jarvinen-Pasley, A., Bellugi, U., Reilly, J., Mills, D. L., Galaburda, A., Reiss, A. L., and Korenberg, J. R. (2008). Defining the social phenotype in Williams syndrome: a model for linking gene, the brain, and behavior. Dev. Psychopathol. 20, 1-35.

John, A. E., and Mervis, C. B. (2010) Comprehension of the communicative intent behind pointing and gazing gestures by young children with Williams syndrome or Down syndrome. J. Speech Lang. Hear. Res. 53 950-960.

Johnston, M. V. (2008). Diffusion tensor imaging of white matter and developmental outcome. Pediatrics 122, 656-657.

Kanwisher, N., McDermott, J., and Chun, M. M. (1997). The fusiform face area: a module in human extrastriate cortex specialized for face perception. J. Neurosci. 17, 4302-4311.

Kanwisher, N., and Yovel, G. (2006) The fusiform face area: a cortical region specialized for the perception of faces. Philos. Trans. R. Soc. Lond. B Biol. Sci. 361, 2109-2128.

Karmiloff-Smith, A., Thomas, M. Annaz, D., Humphreys, K., Ewing,
S., Brace, N., Duuren, M., Pike, G., Grice, S., and Campbell, R. (2004). Exploring the Williams syndrome face-processing debate: the importance of building developmental trajectories. J. Child. Psychol. Psychiatry 45, 1258-1274.

Kim, N., Kim, H. J., Hwang, J., Yoon, S. J., Cho, H. B., Renshaw, P. F., Lyoo, I. K., and Kim, J. E. (2011). Amygdalar shape analysis method using surface contour aligning, spherical mapping, and probabilistic subregional segmentation. Neurosci. Lett. 488, 65-69.

Kippenhan, J. S., Olsen, R. K., Mervis, C. B., Morris, C. A., Kohn, P., Meyer-Lindenberg, A., and Berman, K. F. (2005). Genetic contributions to human gyrification: sulcal morphometry in Williams syndrome. J. Neurosci. 25, 7840-7846.

Klein-Tasman, B. P., and Mervis, C. B. (2003). Distinctive personality characteristics of 8-, 9-, and 10-yearolds with Williams syndrome. Dev Neuropsychol. 23, 269-290.

Klein-Tasman, B. P., Phillips, K. D., Lord, C., Mervis, C. B., and Gallo, F. J. (2009). Overlap with the autism spectrum in young children with Williams syndrome. J. Dev. Behav. Pediatr. 30, 289-299.

Knapska, E., Walasek, G., Nikolaev, E., Neuhausser-Wespy, F., Lipp, H. P., Kaczmarek, L., and Werka, T. (2006). Differential involvement of the central amygdala in appetitive versus aversive learning. Learn. Mem. 13, 192-200.

Kochunov, P., Williamson, D. E., Lancaster, J., Fox, P., Cornell, J., Blangero, J., and Glahn, D. C. (2010). Fractional anisotropy of water diffusion in cerebral white matter across the lifespan. Neurobiol. Aging 33, 9-20.

Koo, J. W., Han, J. S., and Kim, J. J. (2004). Selective neurotoxic lesions of basolateral and central nuclei of the amygdala produce differential effects on fear conditioning. J. Neurosci. 24, 7654-7662.

Lakusta, L., Dessalegn, B., and Landau, B. (2010). Impaired geometric reorientation caused by genetic defect. Proc. Natl. Acad. Sci. U.S.A. 107, 2813-2817.

Landau, B., Hoffman, J. E., and Kurz, N. (2006). Object recognition with severe spatial deficits in Williams syndrome: sparing and breakdown. Cognition 100 483-510.

LeDoux, J. E., Cicchetti, P., Xagoraris, A., and Romanski, L. M. (1990). The lateral amygdaloid nucleus: sensory interface of the amygdala in 
fear conditioning. J. Neurosci. 10, 1062-1069.

Lee, H. J., Gallagher, M., and Holland, P. C. (2010). The central amygdala projection to the substantia nigra reflects prediction error information in appetitive conditioning. Learn. Mem. 17, 531-538.

Lehmann, K., Lesting, J., Polascheck, D., and Teuchert-Noodt, G. (2003). Serotonin fibre densities in subcortical areas: differential effects of isolated rearing and methamphetamine. Brain Res. Dev. Brain Res. 147, 143-152.

Leonard, H. C., Annaz, D., KarmiloffSmith, A., and Johnson, M. H. (2011). Brief report: developing spatial frequency biases for face recognition in autism and williams syndrome. J. Autism Dev. Disord. 41, 968-973.

Lincoln, A. J., Searcy, Y. M., Jones, W., and Lord, C. (2007). Social interaction behaviors discriminate young children with autism and Williams syndrome. J. Am. Acad. Child Adolesc. Psychiatry 46, 323-331.

Mahler, S. V., and Berridge, K. C. (2009). Which cue to "want?" Central amygdala opioid activation enhances and focuses incentive salience on a prepotent reward cue. J. Neurosci. 29, 6500-6513.

Mangin, J. F., Jouvent, E., and Cachia, A. (2011). In-vivo measurement of cortical morphology: means and meanings. Curr. Opin. Neurol. 23, 359-367.

Marenco, S., Siuta, M. A., Kippenhan, J. S., Grodofsky, S., Chang, W. L., Kohn, P., Mervis, C. B., Morris, C. A., Weinberger, D. R., MeyerLindenberg, A., Pierpaoli, C., and Berman, K. F. (2007). Genetic contributions to white matter architecture revealed by diffusion tensor imaging in Williams syndrome. Proc. Natl. Acad. Sci. U.S.A. 104, 15117-15122.

Martens, M. A., Wilson, S. J., Dudgeon, P., and Reutens, D. C. (2009). Approachability and the amygdala: insights from Williams syndrome. Neuropsychologia 47, 2446-2453.

Martens, M. A., Wilson, S. J., and Reutens, D. C. (2008). Research review: Williams syndrome: a critical review of the cognitive, behavioral, and neuroanatomical phenotype. J. Child. Psychol. Psychiatry 49, 576-608.

Maurer, D., O'Craven, K. M., Le Grand, R., Mondloch, C. J., Springer, M. V., Lewis, T. L., and Grady, C. L. (2007). Neural correlates of processing facial identity based on features versus their spacing. Neuropsychologia 45, 1438-1451.

Menghini, D., Addona, F., Costanzo, F., and Vicari, S. (2010). Executive functions in individuals with Williams syndrome. J. Intellect. Disabil. Res. 54, 418-432.

Mervis, C. B., and Klein-Tasman, B. P. (2000). Williams syndrome: cognition, personality, and adaptive behavior. Ment. Retard Dev. Disabil. Res. Rev. 6, 148-158.

Mervis, C. B., Morris, C. A., KleinTasman, B. P., Bertrand, J., Kwitny, S., Appelbaum, L. G., and Rice, C. E. (2003). Attentional characteristics of infants and toddlers with Williams syndrome during triadic interactions. Dev. Neuropsychol. 23, 243-268.

Meyer-Lindenberg, A., Hariri, A. R., Munoz, K. E., Mervis, C. B., Mattay, V. S., Morris, C. A., and Berman, K. F. (2005). Neural correlates of genetically abnormal social cognition in Williams syndrome. Nat. Neurosci. 8, 991-993.

Meyer-Lindenberg, A., Kohn, P., Mervis, C. B., Kippenhan, J. S., Olsen, R. K., Morris, C. A., and Berman, K. F. (2004). Neural basis of genetically determined visuospatial construction deficit in Williams syndrome. Neuron 43, 623-631.

Mimura, M., Hoeft, F., Kato, M., Kobayashi, N., Sheau, K., Piggot, J., Mills, D., Galaburda, A., Korenberg, J. R., Bellugi, U., and Reiss, A. L. (2010). A preliminary study of orbitofrontal activation and hypersociability in Williams Syndrome. J. Neurodev. Disord. 2, 93-98.

Mobbs, D., Eckert, M. A., Mills, D., Korenberg, J., Bellugi, U., Galaburda, A. M., and Reiss, A. L. (2007). Frontostriatal dysfunction during response inhibition in Williams syndrome. Biol. Psychiatry 62, 256-261.

Mobbs, D., Garrett, A. S., Menon, V., Rose, F. E., Bellugi, U., and Reiss, A. L. (2004). Anomalous brain activation during face and gaze processing in Williams syndrome. Neurology 62 , 2070-2076.

Mondloch, C. J., Le Grand, R., and Maurer, D. (2002). Configural face processing develops more slowly than featural face processing. Perception 31, 553-566.

O’Hearn, K., Roth, J. K., Courtney, S. M., Luna, B., Street, W., Terwillinger, R., and Landau, B. (2011). Object recognition in Williams syndrome: uneven ventral stream activation. Dev. Sci. 14, 549-565.

Osborne, L. R. (2010). Animal models of Williams syndrome. Am. J. Med.
Genet. C Semin. Med. Genet. 154C, 209-219.

Papaeliou, C. F., Fryssira, H., Kodakos, A., Kaila, M., Benaveli, E. Michaelides, K., Stroggilos, V. Vrettopoulou, M., and Polemikos, N. (2011). Nonverbal communication, play, and language in Greek young children with Williams syndrome. Child Neuropsychol. 17, 225-241.

Paton, J. J., Belova, M. A., Morrison, S. E., and Salzman, C. D. (2006). The primate amygdala represents the positive and negative value of visual stimuli during learning. Nature 439 , 865-870.

Paul, B. M., Stiles, J., Passarotti, A., Bavar, N., and Bellugi, U. (2002). Face and place processing in Williams syndrome: evidence for a dorsalventral dissociation. Neuroreport 13 1115-1119.

Peelen, M. V., Glaser, B., Vuilleumier, P., and Eliez, S. (2009). Differential development of selectivity for faces and bodies in the fusiform gyrus. Dev. Sci. 12, F16-F25.

Philippi, C. L., Mehta, S., Grabowski, T. Adolphs, R., and Rudrauf, D. (2009). Damage to association fiber tracts impairs recognition of the facial expression of emotion. J. Neurosci. 29, 15089-15099.

Plesa-Skwerer, D., Ammerman, E. Andre, M. C., Ciciolla, L., Fine, A. B., and Tager-Flusberg, H. (2011). A multimeasure approach to investigating affective appraisal of social information in Williams syndrome. J. Neurodev. Disord. 3, 325-334.

Plesa-Skwerer, D., Borum, L., Verbalis, A., Schofield, C., Crawford, N., Ciciolla, L., and Tager-Flusberg, H. (2009). Autonomic responses to dynamic displays of facial expressions in adolescents and adults with Williams syndrome. Soc. Cogn. Affect. Neurosci. 4, 93-100.

Plesa-Skwerer, D., Faja, S., Schofield, C. Verbalis, A., and Tager-Flusberg, $\mathrm{H}$. (2006). Perceiving facial and vocal expressions of emotion in individuals with Williams syndrome. Am. J. Ment. Retard. 111, 15-26.

Porter, M. A., Coltheart, M., and Langdon, R. (2007). The neuropsychological basis of hypersociability in Williams and Down syndrome. Neuropsychologia 45, 2839-2849.

Porter, M. A., Coltheart, M., and Langdon, R. (2008). Theory of mind in Williams syndrome assessed using a nonverbal task. J. Autism Dev. Disord. 38, 806-814.

Porter, M. A., Shaw, T. A., and Marsh, P. J. (2010). An unusual attraction to the eyes in Williams-Beuren syndrome: a manipulation of facial affect while measuring face scanpaths. Cogn. Neuropsychiatry 15, 505-530.

Power, J. D., Fair, D. A., Schlaggar, B. L., and Petersen, S. E. (2010). The development of human functional brain networks. Neuron 67, 735-748.

Proulx, E., Young, E. J., Osborne, L. R., and Lambe, E. K. (2010). Enhanced prefrontal serotonin 5HT(1A) currents in a mouse model of Williams-Beuren syndrome with low innate anxiety. J. Neurodev. Disord. 2, 99-108.

Ramnani, N., Behrens, T. E., Penny, W., and Matthews, P. M. (2004). New approaches for exploring anatomical and functional connectivity in the human brain. Biol. Psychiatry 56, 613-619.

Raznahan, A., Shaw, P., Lalonde, F., Stockman, M., Wallace, G. L., Greenstein, D., Clasen, L., Gogtay, N., and Giedd, J. N. (2011). How does your cortex grow? J. Neurosci. 31, 7174-7177.

Reiss, A. L., and Dant, C. C. (2003). The behavioral neurogenetics of fragile $\mathrm{X}$ syndrome: analyzing genebrain-behavior relationships in child developmental psychopathologies. Dev. Psychopathol. 15, 927-968.

Reiss, A. L., Eckert, M. A., Rose, F. E., Karchemskiy, A., Kesler, S., Chang, M., Reynolds, M. F., Kwon, H., and Galaburda, A. (2004). An experiment of nature: brain anatomy parallels cognition and behavior in Williams syndrome. J. Neurosci. 24, 5009-5015.

Reiss, A. L., Feinstein, C., Rosenbaum, K. N., Borengasser-Caruso, M. A., and Goldsmith, B. M. (1985). Autism associated with Williams syndrome. J. Pediatr. 106, 247-249.

Reiss, A. L., and Hall, S. S. (2007). Fragile $\mathrm{X}$ syndrome: assessment and treatment implications. Child Adolesc. Psychiatr. Clin. N. Am. 16, 663-675.

Riby, D. M., and Hancock, P. J. (2008). Viewing it differently: social scene perception in Williams syndrome and Autism. Neuropsychologia 46, 2855-2860.

Riby, D. M., and Hancock, P. J. (2009). Looking at movies and cartoons: eye-tracking evidence from Williams syndrome and autism. J. Intellect. Disabil. Res. 53, 169-181.

Riby, D. M., Jones, N., Brown, P. H., Robinson, L. J., Langton, S. R., Bruce, V., and Riby, L. M. (2010). Attention to faces in Williams syndrome. J. Autism Dev. Disord. 41, 1228-1239.

Santos, A., and Deruelle, C. (2009). Verbal peaks and visual valleys in theory of mind ability in Williams 
syndrome. J. Autism Dev. Disord. 39, 651-659.

Santos, A., Silva, C., Rosset, D., and Deruelle, C. (2010). Just another face in the crowd: evidence for decreased detection of angry faces in children with Williams syndrome. Neuropsychologia 48, 1071-1078.

Sarpal, D., Buchsbaum, B. R., Kohn, P. D., Kippenhan, J. S., Mervis, C. B., Morris, C. A., Meyer-Lindenberg, A., and Berman, K. F. (2008). A genetic model for understanding higher order visual processing: functional interactions of the ventral visual stream in Williams syndrome. Cereb. Cortex 18, 2402-2409.

Saygin, Z. M., Osher, D. E., Augustinack, J., Fischl, B., and Gabrieli, J. D. (2011). Connectivity-based segmentation of human amygdala nuclei using probabilistic tractography. Neuroimage 56, 1353-1361.

Schmitt, J. E., Watts, K., Eliez, S., Bellugi, U., Galaburda, A. M., and Reiss, A. L. (2002). Increased gyrification in Williams syndrome: evidence using 3D MRI methods. Dev. Med. Child Neurol. 44, 292-295.

Skwerer, D. P., Verbalis, A., Schofield, C., Faja, S., and Tager-Flusberg, H. (2006). Social-perceptual abilities in adolescents and adults with Williams syndrome. Cogn. Neuropsychol. 23, 338-349.

Solano-Castiella, E., Schafer, A., Reimer, E., Turke, E., Proger, T., Lohmann, G., Trampel, R., and Turner, R. (2011). Parcellation of human amygdala in vivo using ultra high field structural MRI. Neuroimage 58, 741-748

Spreng, R. N., Mar, R. A., and Kim, A. S. (2009). The common neural basis of autobiographical memory, prospection, navigation, theory of mind, and the default mode: a quantitative meta-analysis. J. Cogn. Neurosci. 21, 489-510.

Supekar, K., Musen, M., and Menon, V. (2009). Development of largescale functional brain networks in children. PLoS Biol. 7, e1000157. doi:10.1371/journal.pbio.1000157

Tager-Flusberg, H., Plesa-Skwerer, D., Faja, S., and Joseph, R. M. (2003). People with Williams syndrome process faces holistically. Cognition $89,11-24$.

Tager-Flusberg, H., and Sullivan, K. (2000). A componential view of theory of mind: evidence from Williams syndrome. Cognition 76, 59-90.

Takahashi, E., Folkerth, R. D., Galaburda, A. M., and Grant, P. E. (2011). Emerging cerebral connectivity in the human fetal brain: an MR tractography study. Cereb. Cortex 22, 455-464.

Tellegen, A. (1985). "Structures of mood and personality and their relevance to assessing anxiety, with an emphasis on self-report," in Anxiety and the Anxiety Disorders, eds A. H. Tuma and J. Mason (Hillsdale, NJ: Lawrence Erlbaum Associates, Inc.), 681-716.

Thomas, C., Moya, L., Avidan, G., Humphreys, K., Jung, K. J., Peterson, M. A., and Behrmann, M. (2008). Reduction in white matter connectivity, revealed by diffusion tensor imaging, may account for agerelated changes in face perception. J. Cogn. Neurosci. 20, 268-284.

Thomason, M. E., and Thompson, P. M. (2011). Diffusion imaging, white matter, and psychopathology. Annu. Rev. Clin. Psychol. 7, 63-85.

Thompson, P. M., Lee, A. D., Dutton, R. A., Geaga, J. A., Hayashi, K. M., Eckert, M. A., Bellugi, U., Galaburda, A. M., Korenberg, J. R., Mills, D. L., Toga, A. W., and Reiss, A. L. (2005). Abnormal cortical complexity and thickness profiles mapped in Williams syndrome. $J$. Neurosci. 25, 4146-4158.

Todd, R. M., Evans, J. W., Morris, D., Lewis, M. D., and Taylor, M. J. (2010). The changing face of emotion: age-related patterns of amygdala activation to salient faces. Soc. Cogn. Affect. Neurosci. 6, 12-23.

Tomc, S. A., Williamson, N. K., and Pauli, R. M. (1990). Temperament in Williams syndrome. Am. J. Med. Genet. 36, 345-352.

Uddin, L. Q., Iacoboni, M., Lange, C. and Keenan, J. P. (2007). The self and social cognition: the role of cortical midline structures and mirror neurons. Trends Cogn. Sci. (Regul. Ed.) 11, 153-157.

Uddin, L. Q., Supekar, K., and Menon, V. (2010). Typical and atypical development of functional human brain networks: insights from resting-state FMRI. Front. Syst. Neurosi. 4:21. doi:10.3389/fnsys.2010.00021

Van Essen, D. C. (1997). A tensionbased theory of morphogenesis and compact wiring in the central nervous system. Nature 385 , 313-318.

Van Essen, D. C., Dierker, D., Snyder, A. Z., Raichle, M. E., Reiss, A. L., and Korenberg, J. (2006). Symmetry of cortical folding abnormalities in Williams syndrome revealed by surface-based analyses. J. Neurosci. 26, 5470-5483.

Vogel, A. C., Power, J. D., Petersen, S. E. and Schlaggar, B. L. (2010). Development of the brain's functional network architecture. Neuropsychol. Rev. 20, 362-375.

White, T., Su, S., Schmidt, M., Kao C. Y., and Sapiro, G. (2010). The development of gyrification in childhood and adolescence. Brain Cogn. 72, 36-45.
Young, E. J., Lipina, T., Tam, E., Mandel, A., Clapcote, S. J., Bechard, A. R., Chambers, J., Mount, H. T., Fletcher, P. J., Roder, J. C., and Osborne, L. R. (2008). Reduced fear and aggression and altered serotonin metabolism in Gtf2ird1targeted mice. Genes Brain Behav. 7 224-234.

Zahir, F. R., and Brown, C. J. (2011). Epigenetic impacts on neurodevelopment: pathophysiological mechanisms and genetic modes of action. Pediatr. Res. 69, 92R-100R.

Zitzer-Comfort, C., Doyle, T., Masataka, N., Korenberg, J., and Bellugi, U. (2007). Nature and nurture: Williams syndrome across cultures. Dev. Sci. 10, 755-762.

Conflict of Interest Statement: The authors declare that the research was conducted in the absence of any commercial or financial relationships that could be construed as a potential conflict of interest.

Received: 31 January 2012; paper pending published: 16 March 2012; accepted: 21 May 2012; published online: 08 June 2012.

Citation: Haas BW and Reiss AL (2012) Social brain development in Williams syndrome: the current status and directions for future research. Front. Psychology 3:186. doi: 10.3389/fpsyg.2012.00186 This article was submitted to Frontiers in Developmental Psychology, a specialty of Frontiers in Psychology.

Copyright (c) 2012 Haas and Reiss. This is an open-access article distributed under the terms of the Creative Commons Attribution Non Commercial License, which permits non-commercial use, distribution, and reproduction in other forums, provided the original authors and source are credited. 